Check for updates

1 Mayo Clinic, Rochester, Minnesota, US

Cite this as: $B M J 2021 ; 375: n 2886$ http://dx.doi.org/10.1136/bmj.n2886 Published: 23 November 2021

\section{A movement for common care}

Fuelled by the medicalisation of life and an ever-expanding remit, healthcare has become industrialised and unsustainable. Sustainable healthcare requires a shift from industrial healthcare to careful and kind care as well as addressing the social and environmental determinants of health. Caring for, about, and with each other is a social determinant of health, writes Victor Montori

\section{Victor Montori professor of medicine}

\section{Healthcare is unsustainable}

The demand for healthcare services has been growing over recent decades. The medicalisation of suffering and the increase in chronic conditions and premature death-related to the degradation in socioeconomic and environmental conditions of living-have made a patient out of almost everyone. Healthcare's remit is ever increasing. Now, clinicians must screen for social and biomedical risk factors, manage pre-disease states, respond to signals from remote behavioural surveillance devices, certify ailments and disabilities, and, of course, diagnose, treat, palliate, and rehabilitate.

Healthcare organisations are responding to this growing demand with increasing levels of industrialisation: efficiently processing people, treating them according to protocols while limiting access through triage, automatisation, and administrative hindrances. These efforts have produced pathologies of care, ${ }^{1}$ such as cruel delays to accessing care, onerous administrative tasks, "not our job" frustrations when navigating the system, and hurried conversations that result in generic (care for patients like this rather than for this patient) and burdensome care offered by clinicians unfamiliar with and to the patient. Forty percent of patients with multiple chronic conditions report being unable to sustain the work healthcare has delegated on to them ${ }^{2} ; 40 \%$ of healthcare encounters are spent with the clinician attending to the demands of the computer ${ }^{3} ; 40 \%$ of clinicians report symptoms of burnout, with many leaving clinical care or curtailing their patient care hours. ${ }^{4}$ This industrialisation renders healthcare unsustainable to the economies that support it and to the people that try to give and receive care within it. Narrowly focused policy actions seeking to improve access to this unsustainable system, or to improve its efficiency, are unlikely to succeed.

\section{Towards a more sustainable healthcare}

I have proposed a series of actions to turn away from industrial healthcare-an undesirable evolution in human history-and towards careful and kind care for all. ${ }^{5}$ This revolution seeks to enable unhurried conversations between a patient seeking care and a clinician they know and trust. ${ }^{6}$ Within relationships of care, clinicians notice the patient's situation in "high definition," and co-create a sensible and minimally disruptive plan of care with each patient, acting with compassion and competence.
To sustain careful and kind care, it is essential to correct the deficit in the healthcare offer that has accrued at most healthcare systems due to some combination of austerity, profit extraction, poverty, corruption, and incompetence. We must also reduce the demand for healthcare by prioritising care, demedicalising suffering, and addressing social determinants of health. This requires us to promote social justice and address the climate emergency, ${ }^{7}$ Moreover, common care must be radically expanded.

\section{Common care: a social determinant of health}

Everyone needs and expects care from others, particularly at birth, in the first few years of life, when they experience severe illness or disability, and at the end of life. Reciprocally, everyone has a responsibility to care for others. Taking place within families and communities, common care is the hard work of accompanying, alleviating, assisting, and attending to others. ${ }^{89}$ It is the ability and disposition of every person to make the personal, social, and material worlds of another person more able to support their human flourishing. Caring for, about, and with each other ${ }^{10}$ is a social determinant of health.

People, however, are distracted by the media and exhausted by the work of production and consumption. These leave little energy, time, and attention to notice and respond to the needs of others. Care is undervalued, so is acquiring and mastering the skills needed to care for others. I receive many informal consultations via social networking apps from friends and family. These betray their belief that all health concerns require professional care (as all health concerns become medicalised) and that they have no ability to respond carefully. Perhaps healthcare has inadvertently discouraged lay people from acquiring and using common care skills, for example, by disparaging online searches or condemning delays in seeking healthcare.

My hypothesis is that most people in developed countries have not acquired or have lost their common care skills. Thus, when possible, care is outsourced to someone else, frequently to women, and increasingly to low-income, immigrant women from ethnic minorities. ${ }^{11}$ When unavoidable, care giving is lonely and arduous, even when meaningful.

\section{A movement for common care}

Common care, then, must be developed and supported-materially, financially, and socially. Valuing the use of these skills requires changing how 
we work. ${ }^{12} 13$ Acquiring and mastering care skills must be proudly celebrated. Consider how cooking shows have elevated everyday cooking and are helping people to enjoy becoming better at cooking for others. How about learning to accompany, bathe, mobilise, comfort, or feed someone else in need of care?

The pandemic has revealed to a generation of children the true extent of our interdependence. It has taught them how much, when scared, desperate, and confused, people care for and about each other, organise mutual aid, and appreciate the work of care givers, honouring them with applause, calling them heroes. ${ }^{14}$ These children could grow up valuing care, acquiring the skills of common care at home and at school, and equating success in life with becoming the most caring and careful persons they can be.

A common care movement could develop our collective capacity to care for, about, and with each other, distribute the responsibilities of care more equitably, enable a more sustainable and caring healthcare, and bring about a post pandemic world which is better able to support humans to flourish. We need a movement for common care.

Competing interests: Victor Montori is a clinician, researcher, and care activist. He is professor of medicine and participates in the care of people with diabetes at the Mayo Clinic in Rochester, Minnesota, US. He has written a book called Why We Revolt. He chairs the board of The Patient Revolution, an international charity working for careful and kind care for all. I don't derive any income for his service to the charity or royalties from the book. Any royalties are deposited directly into the charity's account.

Provenance and peer review: commissioned, not peer reviewed

1 Allwood D, Koka S, Armbruster R, et al. Leadership for careful and kind care. BMJ Leader 2021:leader-2021-000451. doi: 10.1136/leader-2021-000451

2 Tran VT, Montori VM, Ravaud P. Is My Patient Overwhelmed?: Determining Thresholds for Acceptable Burden of Treatment Using Data From the ComPaRe e-Cohort. Mayo Clin Proc 2020;95:504-12. doi: 10.1016/j.mayocp.2019.09.004. pmid: 31619365

3 Pinevich Y, Clark KJ, Harrison AM, Pickering BW, Herasevich V. Interaction Time with Electronic Health Records: A Systematic Review. Appl Clin Inform 2021;12:788-99. doi: 10.1055/s-0041-1733909. pmid: 34433218

4 West CP, Dyrbye LN, Shanafelt TD. Physician burnout: contributors, consequences and solutions. J Intern Med 2018;283:516-29. doi: 10.1111/joim.12752. pmid: 29505159

5 Montori V. Why We Revolt: A Patient Revolution for Careful and Kind Care. Patient Revolution, 2017.

6 Montori V, Hargraves I, Breslin M, et al. Careful and kind care requires unhurried conversations 2019. https://catalyst.nejm.org/doi/full/10.1056/CAT.19.0696

7 Marmot M, Allen J, Goldblatt P, etal. Build Back Fairer: The COVID-19 Marmot Review. The Pandemic, Socioeconomic and Health Inequalities in England. Institute of Health Equity, 2020.

8 Kleinman A. Varieties of Experiences of Care. Perspect Biol Med 2020;63:458-65. doi: 10.1353/pbm.2020.0033. pmid: 33416619

9 Camps V. Tiempo de cuidados. Otra forma de estar en el mundo. Arpa Editories, 2021.

10 Tronto J. Who Cares? How to reshape a democratic politics. Cornell University Press, 2015.

11 Dowling E. The Care Crisis. What caused it and how can we end it? Verso, 2021.

12 Haraldsson G, Kellam J. Going public: Iceland's journey to a shorter working week. Association for Democracy and Sustainability, and Autonomy, 2021.

13 The Care Collective. Chatzidakis A, Hakim J, et al. The Care Manifesto: The politics of interdependence. Verso, 2020.

14 Tolentino J. What mutual aid can do during a pandemic. A radical practice is suddenly getting mainstream attention. Will it change how we help one another? The New Yorker, 2020. 